\title{
Geometrifade $\mathfrak{Z}_{\text {ufgaben }}$
}

\section{und $\mathfrak{u}$ bungen \\ für $\mathfrak{b}$ öberectebranftalten \\ a116}

Meblers Ђaupträt5en ber Kementar Matbematif

(2urgabe B)

bearbeitet von

Wberfubienditetror Şhulte: Tigges

Unter|tufe

Init 2 Taficln

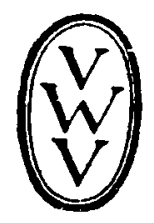

Żerlin uno Reipzig 1923

Derlag von $\mathfrak{W}_{\text {alter }}$ of Grupter \& $\mathbb{C}_{0}$.

rovmals G. I. Gojiden'idge Derlaggbandlung . J. Guttentag, Vetlagsbud.

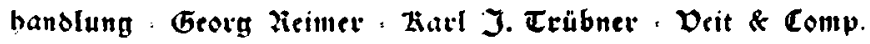


